first-class scientific contributions in an atmosphere of academic freedom. Nobel laureates Hideki Yukawa and San'ichiro Tomonaga worked there, for example. Nevertheless, expansion of scientific institutions was restricted, and Bartholomew's account shows clearly the origins of today's political bureaucracy.

Bartholomew covers the formation of science in Japan up to the 1920s. His is a crisp, readable account, based on numerous government documents and other sources written in Japanese. No study as thorough as this one exists, even in Japanese, and it is full of little-known facts - for example, I did not know that the present began as early as 1918 . Ministry of Education's research grant

In 1939, television broadcasts were demonstrated for the first time at the World Fair in New York. It took only 14 years for television to reach Tokyo, and today every US resident enjoys watching Japanese-made television sets. Bartholomew provides an explanation for the underlying basis of Japan's technological successes up until the 1920s: efficient imitation of Western science - but with some original developments - after a long period of isolation. He now has another task in analysing the post-war boom in Japanese science and technology.

Koscak Maruyama is in the Department of Biology, Faculty of Science, Chiba University, Yayoi-oho, Chiba 260, Japan.

\section{Clever chaps}

\section{John Currey}

On Biomineralization. By Heinz A. Lowenstam and Stephen Weiner. Oxford University Press: 1989. Pp. 324. £40, \$57.

Biomineralization. By Kenneth Simkiss and Karl M. Wilbur. Academic: 1989. $£ 50, \$ 69.95$.

Biomineralization: Chemical and Biochemical Perspectives. Edited by $\mathrm{S}$. Mann, J. Webb and R. J. Williams. VCH: 1989. Pp. 541. DM 274, $\$ 98$.

ALL the main groups of organisms contain members that make use of minerals in their bodies. Most obviously, a mineral is used to produce skeletons for protection and support, but minerals are put to many other uses - as gravity and inertia sensors, as sensors of the Earth's magnetic field, as optical systems and as stores of the ions of the mineral. Materials scientists faced with the task of making skeletal materials within the constraints that living organisms endure would probably resign. Among these constraints are that the materials must be available locally, that the processing must take place almost at equilibrium at all times, in the temperature range 0 to $40{ }^{\circ} \mathrm{C}$, without any large energy inputs and that, as organisms grow, the skeleton must be functional at all stages in the life history.

Organisms do have some advantages, however. Often the rate of formation of the skeleton is not critical. Also, organisms can control the ionic constitution of their body fluids, and of fluids just outside their bodies, with extraordinary precision, and the composition can be varied by orders of magnitude over very small distances. The tonoplast membrane of plant cells separates compartments differing in calcium-ion concentration by a factor of $10^{5}$ over a distance of 10 nanometres. Such precision enables organisms to produce structures of great delicacy or robustness as required. The study of these developmental processes is coming into its own, and the rather remarkable appearance of three substantial books with virtually the same title, within a few months of each other, is an indication of this.

Two of the books, by Lowenstam and Weiner (Lowenstam), and Simkiss and Wilbur (Simkiss), are very similar in their approach. They deal with general issues such as the control of mineralization (Simkiss), biogeochemical cycles (Simkiss), environmental influences on biomineralization (Lowenstam) and the evolution of biomineralization (Lowenstam), but their main focus is taxonomic, with discussion of the kinds of biomineralization processes found in the major groups, and of the anatomy and microanatomy of the structures produced. Both books are well illustrated, particularly Simkiss. Lowenstam is about 50 per cent longer, and goes more deeply into a number of subjects. Simkiss is written at a slightly lower technical level, containing more deft turns of phrase and interesting asides. Both books are remarkably readable considering their complex subject matter. The ability of organisms to mould the form of minerals coming out of solution is at times almost literally incredible. I found myself turning the pages with rather naive excitement, wondering "whatever next?".

The profusely illustrated book edited by Mann, Webb and Williams covers much of the same ground but at considerably greater length. Each of the fifteen chapters tends to be focused on a particular, often rather restricted topic. As a result there is no real attempt at a comprehensive coverage. The discussion of vertebrate hard tissue, for instance, is limited almost entirely to 29 pages by Viess on the organic components of teeth. There is virtually no mention of bone or eggshells, and otoconia are mentioned in passing elsewhere in the book. Simkiss gives a few pages to each of these last topics, but does not mention dental tissues. Lowenstam gives the full treatment - more than 50 pages - to chordate hard tissues, but barely mentions eggshells.

This eclectic approach is not taken to extremes in Mann et al. , in which mineralization in most groups is discussed. Some chapters are a delight; those by Mann and Frankel on magnetitie in microorganisms, by Addadi and Weiner on organic/inorganic relations in mineralization, and by Mann on "Crystallochemical Strategies in Biomineralization", are particularly interesting, but there will be certainly many others of value to anyone interested in biomineralization. In general, of course, the extended coverage gives a more satisfying account of the chosen topics than is found in the other two books. Mann et al. contains several chapters on analytical techniques that are becoming increasingly important, such as nuclear magnetic resonance, infrared, ultraviolet, and Mössbauer spectroscopies, high-resolution transmission electron microscopy, and proton beam analysis.

It is always a temptation to criticize books for not doing what they do not attempt; both Simkiss and Mann et al. emphasize their chemical, biochemical and cell-biological orientation in their subtitles. But it is disconcerting that these books reflect so little consideration of the function of the finished products. This lack is particularly obvious in the chapters devoted to skeletons. Foraminiferans and coccolithophorids have extremely complex skeletons, whose shapes are virtually fixed within species but vary considerably between species. For example, I would like to know whether this matters to the organism; does the precise shape of its skeleton have an adaptive value that would be less if the skeleton were different? Again, the organic matrix is repeatedly shown in these books to have a crucial role in the control of mineralization. Yet we also know that microanatomy produced by the presence of the organic matrix, and the organic matrix itself, have a profound effect on the mechanical properties of the resulting skeleton. Except for a short section in the chapter by Birchall in Mann et al., dealing with the insights to be gained by technologists from biomineralization, this dual role of the organic constituents of mineralized skeletons is barely mentioned.

Publication of these three books leaves graduate students starting work on biomineralization in an enviable position. There are now two excellent accounts providing an overview of the subject; they should certainly buy one. And the third gives insight into the state of research in many parts of the field, research that is beginning to produce exciting answers to difficult questions. The subject is growing up.

John Currey is Professor of Biology, University of York, York YO1 5DD, UK. 